Polycarbonate-based ordered arrays of electrochemical nanoelectrodes obtained by e-beam lithography

This article has been downloaded from IOPscience. Please scroll down to see the full text article.

2011 Nanotechnology 22185305

(http://iopscience.iop.org/0957-4484/22/18/185305)

View the table of contents for this issue, or go to the journal homepage for more

Download details:

IP Address: 157.138.10.3

The article was downloaded on 20/04/2011 at 10:50

Please note that terms and conditions apply. 


\title{
Polycarbonate-based ordered arrays of electrochemical nanoelectrodes obtained by e-beam lithography
}

\author{
L M Moretto ${ }^{1}$, M Tormen ${ }^{2}, \mathrm{M}$ De Leo ${ }^{1}$, A Carpentiero ${ }^{2}$ and P Ugo ${ }^{1}$ \\ ${ }^{1}$ Department of Molecular Sciences and Nanosystems, University Ca' Foscari of Venice, \\ Santa Marta 2137, 30123 Venice, Italy \\ ${ }^{2}$ CNR-IOM, TASC Laboratory, Basovizza S S 14 km 163.5, 34149 Trieste, Italy \\ E-mail: ugo@unive.it
}

Received 29 October 2010, in final form 22 February 2011

Published 22 March 2011

Online at stacks.iop.org/Nano/22/185305

\begin{abstract}
Ordered arrays of nanoelectrodes for electrochemical use are prepared by electron beam lithography (EBL) using polycarbonate as a novel e-beam resist. The nanoelectrodes are fabricated by patterning arrays of holes in a thin film of polycarbonate spin-coated on a gold layer on $\mathrm{Si} / \mathrm{Si}_{3} \mathrm{~N}_{4}$ substrate. Experimental parameters for the successful use of polycarbonate as high resolution EBL resist are optimized. The holes can be filled partially or completely by electrochemical deposition of gold. This enables the preparation of arrays of nanoelectrodes with different recession degree and geometrical characteristics. The polycarbonate is kept on-site and used as the insulator that separates the nanoelectrodes. The obtained nanoelectrode arrays (NEAs) exhibit steady state current controlled by pure radial diffusion in cyclic voltammetry for scan rates up to approximately $50 \mathrm{mV} \mathrm{s}^{-1}$. Electrochemical results showed satisfactory agreement between experimental voltammograms and suitable theoretical models. Finally, the peculiarities of NEAs versus ensembles of nanoelectrodes, obtained by membrane template synthesis, are critically evaluated.
\end{abstract}

(Some figures in this article are in colour only in the electronic version)

\section{Introduction}

Sub-micrometre sized electrodes have become progressively more widely used for analytical applications thanks to the development of relatively easy nanofabrication procedures providing arrays or ensembles of nanodisc [1-4], or nanowire and nanocone electrodes [5-7]. Arrays and ensembles have indeed the advantage of furnishing higher signals than individual nanoelectrodes, so that they do not require sophisticated electronic amplification. Moreover, when composed by a large number of nanoelectrode elements they are less sensitive to fabrication defects, if these defects affect only a small number (statistically negligible) of elements of the array. Note that here we use the definition introduced by Martin in 1995 [1] and followed by others [2, 7], where, in the nanoelectrode ensemble (NEE) and in the nanoelectrode array (NEA), individual nanoelectrodes are random or orderly distributed, respectively.

Bottom-up technologies, such as the template-based methods exploiting nanoporous membranes [1-3], selfassembly of block copolymers [8], defects in self-assembled (mono)layers [9], are often used for obtaining NEEs. Topdown techniques, such as ion beam lithography [4, 10, 11], electron beam lithography (EBL) [12], nanoimprint [13] or scanning probe lithography $[14,15]$, allow one to achieve high resolution nanostructuring, providing a precise positioning and sizing down to a scale of a few nanometres.

With respect to conventional macro (mm-sized) or even ultramicro ( $\mu \mathrm{m}$-sized) electrodes, NEEs/NEAs present remarkably lower double layer charging currents, enhanced mass fluxes and extreme sensitivity to the electron transfer kinetics $[1,3,4,16]$. Depending on the distance between the nanoelectrode elements [17], the scan rate [17] and 
the viscosity of the electrolyte [18, 19], different diffusion regimes can be observed. They are [1, 2, 20, 21]: (A) total overlap regime, when radial diffusion boundary layers overlap totally; (B) pure radial, when the nanoelectrodes behave independently; (C) linear active, when the nanoelectrodes behave as isolated planar electrodes; (D) mixed diffusion regimes, that are regimes intermediate between cases (A) and (B). Both NEEs and NEAs can be used to prepare highly miniaturized electrode systems with improved $\mathrm{S} / \mathrm{N}$ ratio [1, 2, 16, 22], which can be functionalized for biosensing purposes [6, 23, 24].

Several theoretical models address the electrochemical behaviour of arrays of inlaid or recessed nanoelectrodes [20, 21, 25-28]. On the contrary, relatively few examples of effective nanofabrication methods for the preparation of ordered arrays of nanoelectrodes have been presented up to now. Errachid et al [10] and Arrigan's group [11] reported on the preparation and properties of arrays of recessed nanodisc electrodes surrounded by an insulating layer of $\mathrm{Si}_{3} \mathrm{~N}_{4}$. Interdigitated gold nanoelectrodes were prepared on glass [29] or $\mathrm{SiO}_{2}$ [30] as the insulator interposed between the electrodes. Godino et al [25] presented arrays made of a relatively small number of nanoelectrodes (namely, 16) prepared by EBL on poly(methyl methacrylate) (PMMA) as ebeam resist. Previously, Sandison and Cooper [12] prepared arrays of recessed gold nanodisc electrodes obtained by EBL and used as electrodes without removing the PMMA resist.

The idea behind the present study is to combine the principle of defining the geometry of the nanoelectrodes by opening holes in a polymer thin film (which acts as the insulator between the electrodes) with the prospect of using the polymer itself as a platform for further (bio)chemical functionalization [24, 31]. Preliminary experiments performed in our laboratory, aimed at preparing NEA with PMMA as e-beam resist and insulator [32], did not provide completely satisfactory results, in particular as far as stability and reproducibility in electrolyte solution were concerned. For these reasons, in the present work we studied the possibility of using a commercially available polycarbonate (PC), based on bisphenol-A, as a novel resist for high resolution EBL, for NEAs' fabrication. Some years ago, Harnett et al [33] presented a study on the use of a different kind of polycarbonate, namely poly(cyclohexane carbonate) as a sacrificial layer in EBL. However, the latter polymer needs to be prepared on purpose and is not as well standardized as is bisphenol-A; moreover it requires solvents and developers unsuitable for the present purpose. Indeed, 'classical' PC presents interesting properties since it is temperature resistant, has very good optical properties and rather good chemical compatibility and, most importantly, can be easily functionalized with biomolecules for advanced biorecognition purposes [24, 31, 32, 34, 35]. To the best of our knowledge, this is the first report demonstrating that commercially available bisphenol-A polycarbonate can be successfully employed as an e-beam resist for high resolution EBL (down to the tens of nanometre range) and as an insulating layer in NEAs.

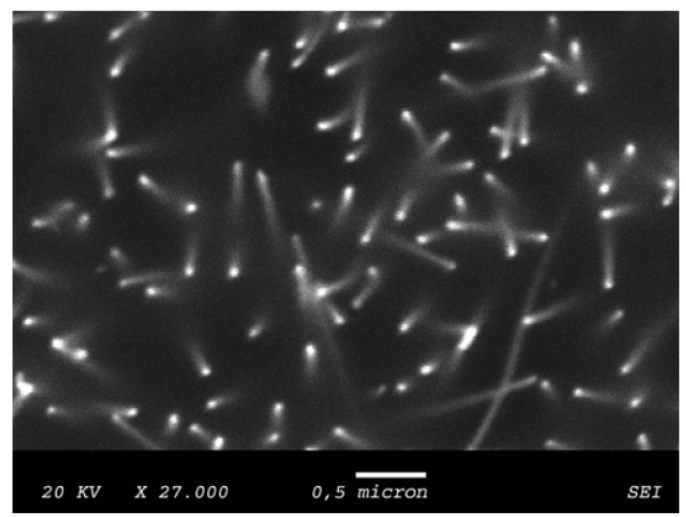

Figure 1. SEM image of a NEE prepared using a track-etched PC membrane $(30 \mathrm{~nm}$ pore diameter).

\section{Experimental section}

\subsection{Materials and apparatus}

$\alpha$-methylferrocene methanol (FE) was from Sigma Aldrich, other chemicals were of analytical grade and used as received. Purified water was obtained by a Milli-Ro plus Milli- $Q$ (Millipore) system. Electroanalytical measurements were carried out at room temperature $\left(22 \pm 1^{\circ} \mathrm{C}\right)$ in a three-electrode cell with a platinum coil counter electrode and an $\mathrm{Ag} / \mathrm{AgCl}$ ( $\mathrm{KCl}$ saturated) reference electrode, connected to a $\mathrm{CHI}$ Model $660 \mathrm{~A}$ potentiostat. EBL was performed using a Zeiss $1540 \mathrm{XB}$ cross beam system.

\subsection{Arrays and ensembles of nanoelectrodes}

NEEs were prepared following the procedure introduced by Menon and Martin [1], using recent improvements which allow a better control of the process $[3,6,36]$. Figure 1 shows the scanning electron microscopy (SEM) image of a NEE obtained by this procedure.

NEAs were prepared by the following procedure. A solution $3.2 \% \mathrm{w} / \mathrm{v}$ of PC in cyclopentanone was deposited by spin-coating on a Au film (20 nm thickness) deposited by thermal evaporation in high vacuum on $\mathrm{Si} / \mathrm{Si}_{3} \mathrm{~N}_{4}$. In order to improve adhesion of the $\mathrm{Au}$ film a thin $\mathrm{Cr}$ layer $(5 \mathrm{~nm}$ thick) was pre-evaporated. Spin-coating of PC solution was performed at rotational speeds ranging between 1500 and $6000 \mathrm{rpm}$; resulting thicknesses (measured with a Dektak profilometer) ranged from 450 (at $1500 \mathrm{rpm}$ ) to $50 \mathrm{~nm}$ (at $6000 \mathrm{rpm}$ ). The spin-coating was followed by annealing at $170{ }^{\circ} \mathrm{C}$ for $5 \mathrm{~min}$. Test patterns were exposed to a focused electron beam. The development was performed in $5 \mathrm{M}$ $\mathrm{NaOH}$ solution at different temperatures, between 20 and $70{ }^{\circ} \mathrm{C}$, followed by rinsing with water. Electrodeposition of gold within the holes was performed galvanostatically using a commercial gold bath (Karatclad, Grauer and Weil (India) Ltd), at a current density of $10 \mathrm{~mA} \mathrm{~cm}^{-2}$.

The main geometrical characteristics of the arrays and ensembles studied in this work are summarized in table 1. 

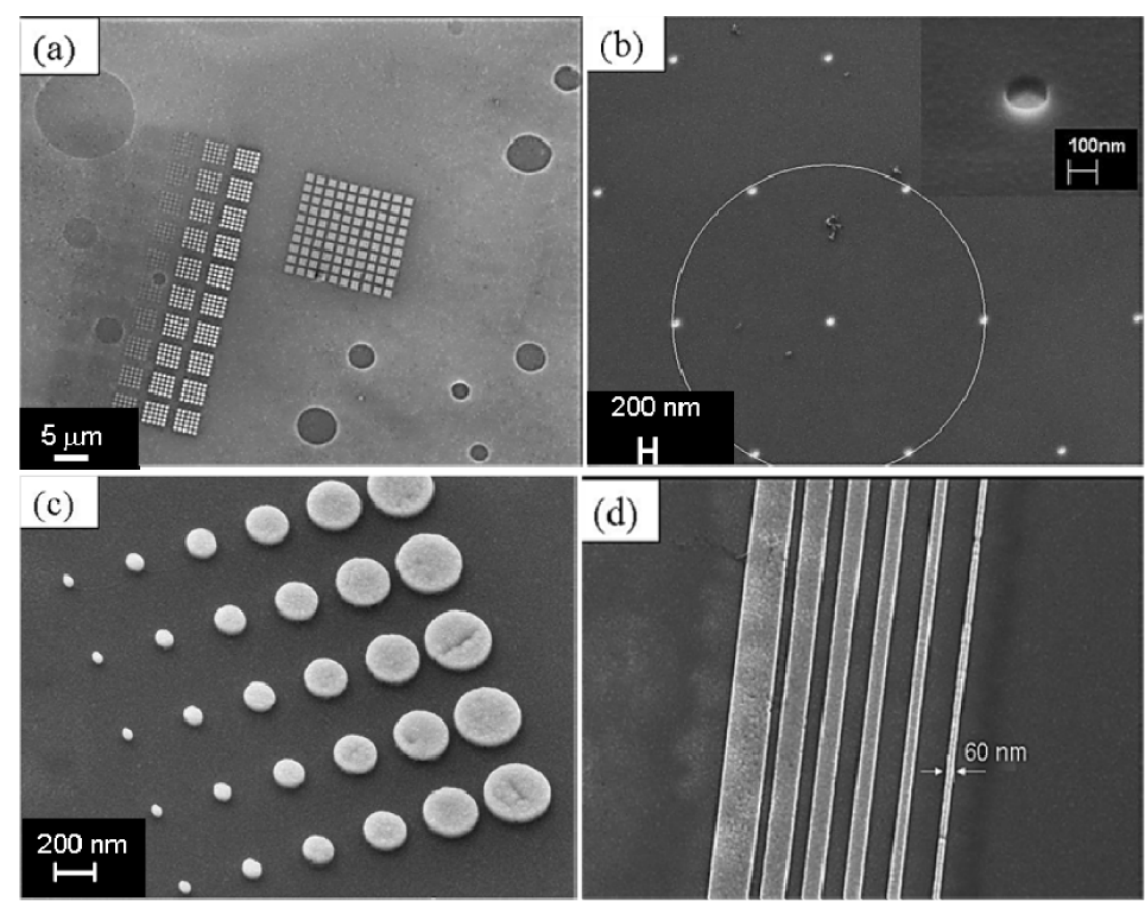

Figure 2. (a) SEM micrograph of a dose matrix test developed at $70{ }^{\circ} \mathrm{C}$ for $60 \mathrm{~s}$. Large pinholes appear on the polycarbonate film; (b) top view of $75 \mathrm{~nm}$ radius dots in a hexagonal array on PC film after $E$-beam exposure; inset: higher magnification detail; (c) electroplated gold dots of various sizes down to $50 \mathrm{~nm}$; (d) nanobands with different widths.

Table 1. Geometrical characteristics of the arrays (NEA) and ensembles (NEE) of nanoelectrodes.

\begin{tabular}{lll}
\hline & NEA & NEE \\
\hline Outer shape and overall geometry & Square, $300 \mu \mathrm{m} \times 300 \mu \mathrm{m}$ & Circular, diameter 3 mm \\
Distribution of the electrodes within the array & Hexagonal & Random \\
Nanodisc radius & $75 \mathrm{~nm}$ & $15 \mathrm{~nm}$ \\
Distance centre-to-centre & $3 \mu \mathrm{m}$ & Average 200 nm \\
Recession depth & From 0 to $400 \mathrm{~nm}$ & Nominally inlaid \\
Estimated number of nanoelectrodes in the array & $1.1 \times 10^{4}$ & $4.2 \times 10^{7}$ \\
Nanoelectrodes density (nanoelectrode $\mathrm{cm}^{-2}$ ) & $1.2 \times 10^{7}$ & $6 \times 10^{8}$ \\
\hline
\end{tabular}

\section{Results and discussion}

\subsection{Optimization of parameters for NEA fabrication}

The procedure here proposed for EBL on polycarbonate was inspired by the fabrication technology of track-etch membranes used for NEE preparation [3], in which heavy ions are used to produce long cylindrical pores, random distributed, in polymeric materials [37]. Energetic heavy ions passing in the material create tracks that etch in concentrated alkaline solutions $(\mathrm{NaOH})$ at a very different rate $\left(V_{\mathrm{t}}\right)$ from that of the bulk $\left(V_{\mathrm{b}}\right)$. In polycarbonate, the etching rate ratio $V_{\mathrm{t}} / V_{\mathrm{b}}$ is between $10^{2}$ and $10^{5}$ [38]. In the present work we adapted the PC track-etch process to the case of radiation damage produced by an energetic electron beam controlled in an advanced EBL system to fabricate ordered NEAs. The NEAs used for lithographic tests were prepared using a gold film evaporated on silicon as substrate so that the gold will act as a recessed electrode after the opening of holes in the polycarbonate film. Note that the Au film is necessary also to protect the silicon substrate during the development which is performed in $\mathrm{NaOH}$ solution.
Given the unavailability of literature data, a broad dose range between 20 and $20000 \mu \mathrm{C} \mathrm{cm}^{-2}$ at $30 \mathrm{kV}$ acceleration voltage was tested. The pattern for the dose matrix consisted of a $10 \times 10$ array of dots. The resist was deposited by spincoating at $2000 \mathrm{rpm}$ and was then baked at $170^{\circ} \mathrm{C}$ for $5 \mathrm{~min}$ (thickness $120 \mathrm{~nm}$ ) and developed in $5 \mathrm{M} \mathrm{NaOH}$ at $50^{\circ} \mathrm{C}$ for $45 \mathrm{~min}$.

The conditions for the development process were optimized by changing the temperature of the $\mathrm{NaOH}$ solution from 20 to $70^{\circ} \mathrm{C}$. The formation of large pinholes in the polymer film (see figure 2(a)) was observed when the development was carried out at $70{ }^{\circ} \mathrm{C}$, suggesting that the suitable temperature window for the development is in the range from 20 to $60^{\circ} \mathrm{C}$. Moreover, it was observed that the optimal dose for development performed at $50^{\circ} \mathrm{C}$ is $2000 \mu \mathrm{C} \mathrm{cm}^{-2}$ at $30 \mathrm{kV}$. Figure 2(b) shows a top view of $75 \mathrm{~nm}$ radius dots in a hexagonal array on PC film after e-beam exposure and development.

In order to inspect high resolution pattern (holes) and to verify that the developer reached the conductive gold film, gold was electrodeposited inside the holes using the $\mathrm{Au}$ on 


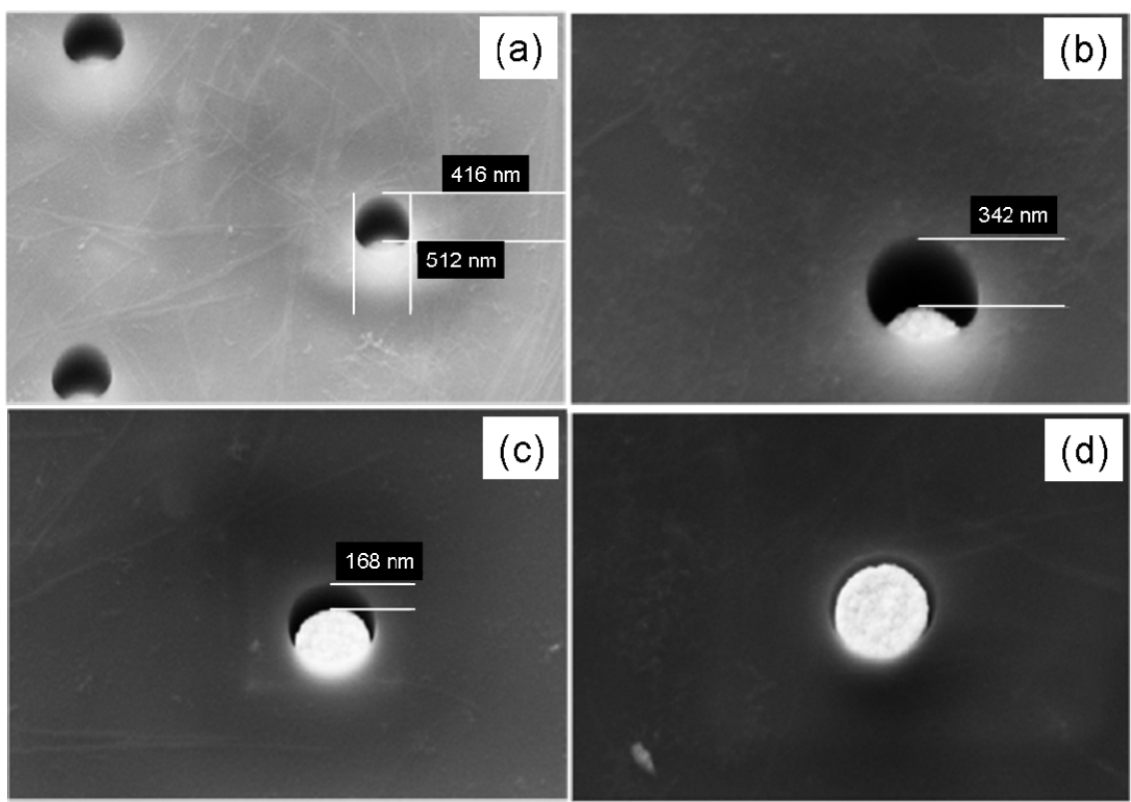

Figure 3. SEM images of NEAs with dots of $r=250 \mathrm{~nm}$ with gold deposited electrochemically inside for $0 \mathrm{~s}$ (a), $10 \mathrm{~s}$ (b), $20 \mathrm{~s}$ (c) and $30 \mathrm{~s}$ (d). Estimated recession depths: (a) $450 \mathrm{~nm}$; (b) $300 \mathrm{~nm}$; (c) $150 \mathrm{~nm}$; (d) $0 \mathrm{~nm}$.

the bottom of the holes as electrode for the electroplating. Figure 2(c) shows the high resolution rods electroplated inside holes in spin-coated polycarbonate after removal of the polymer, with different diameters ranging from $600 \mathrm{~nm}$ down to $50 \mathrm{~nm}$. This image shows that the holes were completely opened during the development so that gold nanorods were formed by the electroplating. Figure 2(d) shows that also lines of finely controlled width can be obtained; however, in the following we will focus only on disc or hole electrodes. This evidence confirms the suitability of PC for high resolution patterning by EBL.

Figures 3 shows the SEM images of dots partially or completely filled with electroplated gold, prepared using different electroplating time, namely $0,10,20$ and $30 \mathrm{~s}$, respectively. These results confirm that the recession depth $(l)$ can be controlled at pleasure since it decreases with increasing the deposition time. It is worth mentioning that measured $l$ values are in agreement with the values calculated on the basis of the charge involved in the deposition process. However, some cracks were observed between the gold deposited and the polycarbonate. This problem was minimized by heating at $155^{\circ} \mathrm{C}\left(\mathrm{PC}\right.$ glass transition temperature is $150{ }^{\circ} \mathrm{C}$ [1] ) for $15 \mathrm{~min}$; the shrinking of the PC allowed the lateral sealing of the nanoelectrodes.

\subsection{Electrochemical characterization of NEAs}

NEAs prepared following the optimized procedure above described, were tested electrochemically by using FE as a reversible redox probe [39]. Figure 4(a) shows the cyclic voltammograms recorded at a scan rate $(v)$ of $10 \mathrm{mV} \mathrm{s}^{-1}$ with an NEA composed of a $75 \mathrm{~nm}$ radius dot with $100 \mathrm{~nm}$ recession depth in a hexagonal array on a PC film in $10^{-4} \mathrm{M} \mathrm{FE}$ and $\mathrm{NaNO}_{3}$ as the supporting electrolyte of concentration 0.01 or $0.5 \mathrm{M}$ (dashed and solid line, respectively). The voltammetric patterns are sigmoidally shaped, indicating a radial diffusion regime. Godino et al [25] observed sigmoidal CVs using NEAs of very small overall dimension $(15 \mu \mathrm{m} \times 15 \mu \mathrm{m}$, for 16 nanoelectrodes) even when the nanoelectrodes crosstalk each other, since lateral diffusion at the perimeter of the overall array dominated the process. This is not the case here, where the number of nanoelectrodes at the perimeter of the field is statistically negligible with respect to the total number of nanoelectrodes (see table 1). This is reflected also in the recording of rather large steady state currents (of the order of $2 \times 10^{-8} \mathrm{~A}$ ), even if the analyte concentration is quite low $\left(10^{-4} \mathrm{M}\right)$. This evidence indicates that, in our NEA, the sigmoidal shape of the $\mathrm{CV}$ is due to the occurrence of the pure radial regime, that is, the diffusion hemispheres around individual nanoelectrodes do not overlap and there is no crosstalk between the electrodes.

For comparison, figure 4(b) shows the cyclic voltammogram recorded at an NEE at the same scan rate as in figure 4(a). It was previously proved that peak-shaped voltammograms obtained at NEEs are due to the operativity of the total overlap diffusion regime [1-3]. At the NEA, a slightly higher current signal is recorded at higher supporting electrolyte concentration, as shown by the solid line curve in figure 4(a). This is probably related to the role of the electrical resistance of the electrolyte solution which is known to play a relevant role producing some distortion of voltammetric responses at recessed nanoelectrodes [11].

Figure 5 compares the current densities for the same NEE and NEA in figure 4, calculated with respect to the geometric area (figure 5(a)) and active area (figure 5(b)). The geometric area is defined as the overall area of the nanoelectrodes plus insulator exposed to the sample solution; the active area is the overall area of the nanoelectrodes alone [1]. As expected on the basis of previous considerations $[2,3]$, the current density 

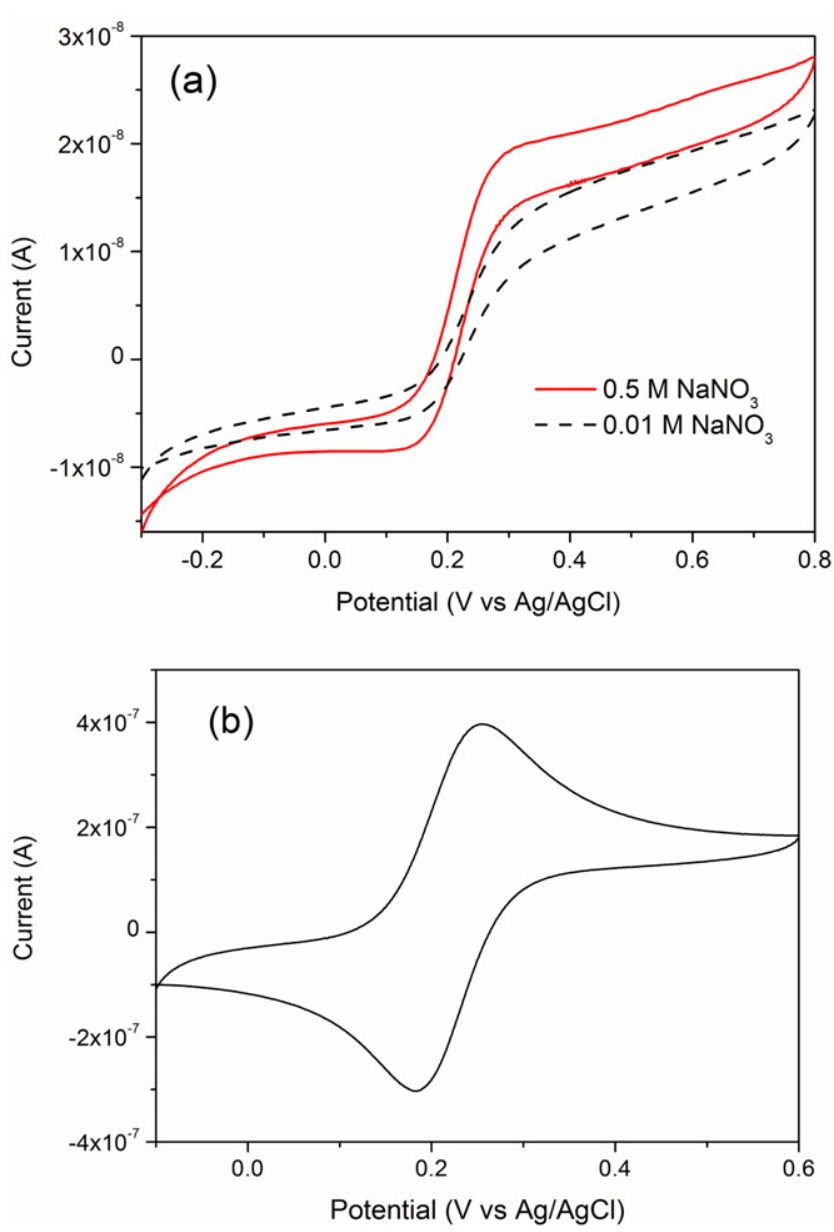

Figure 4. $\mathrm{CV}$ s recorded at $10 \mathrm{mV} \mathrm{s}^{-1}$ in $10^{-4} \mathrm{M} \mathrm{FE}$ : (a) at an NEA (nanoelectrode radius $75 \mathrm{~nm}$, recession depth $100 \mathrm{~nm}$ ) in $0.5 \mathrm{M}$ $\mathrm{NaNO}_{3}$ (full line) and $0.01 \mathrm{M} \mathrm{NaNO}_{3}$ (dashed line); (b) at an NEE (nanoelectrode radius $15 \mathrm{~nm}$ ) in $1 \mathrm{mM} \mathrm{NaNO}_{3}$. For other geometrical parameters see table 1 .

of the NEE is higher than at the NEA if the overall geometric area of the array is taken into account. The opposite is true, that is the current density is higher at the NEA versus NEE when the current density is evaluated with respect to the active area. This is because at the NEE in total overlap condition, $100 \%$ of the geometric area contributes to producing the faradic signal, while at the NEA under pure radial conditions, the nanoelectrodes do not cross-talk and the transduction efficiency at each nanoelectrode reaches its maximum [20, 27]; however, at NEAs the percentage of geometric area taking part in the diffusion of the analyte is less than $100 \%$ of the overall geometric area of the array.

As shown in figure 6, sigmoidally shaped $\mathrm{CV}$ s are observed at our NEA over a relatively broad range of scan rates $\left(5-50 \mathrm{mV} \mathrm{s}^{-1}\right)$. Under these conditions the only current signal that changes is the double layer charging current, which increases with the scan rate, while the faradic limit current remains constant. As shown in figure 7(a), a transition from sigmoidal, to mixed, to peak-shaped CVs was observed at higher scan rates, namely $\geqslant 100 \mathrm{mV} \mathrm{s}^{-1}$.

Taking into account that the nanoelectrodes in the array are recessed, the sigmoidal shape of the CVs for $v<$
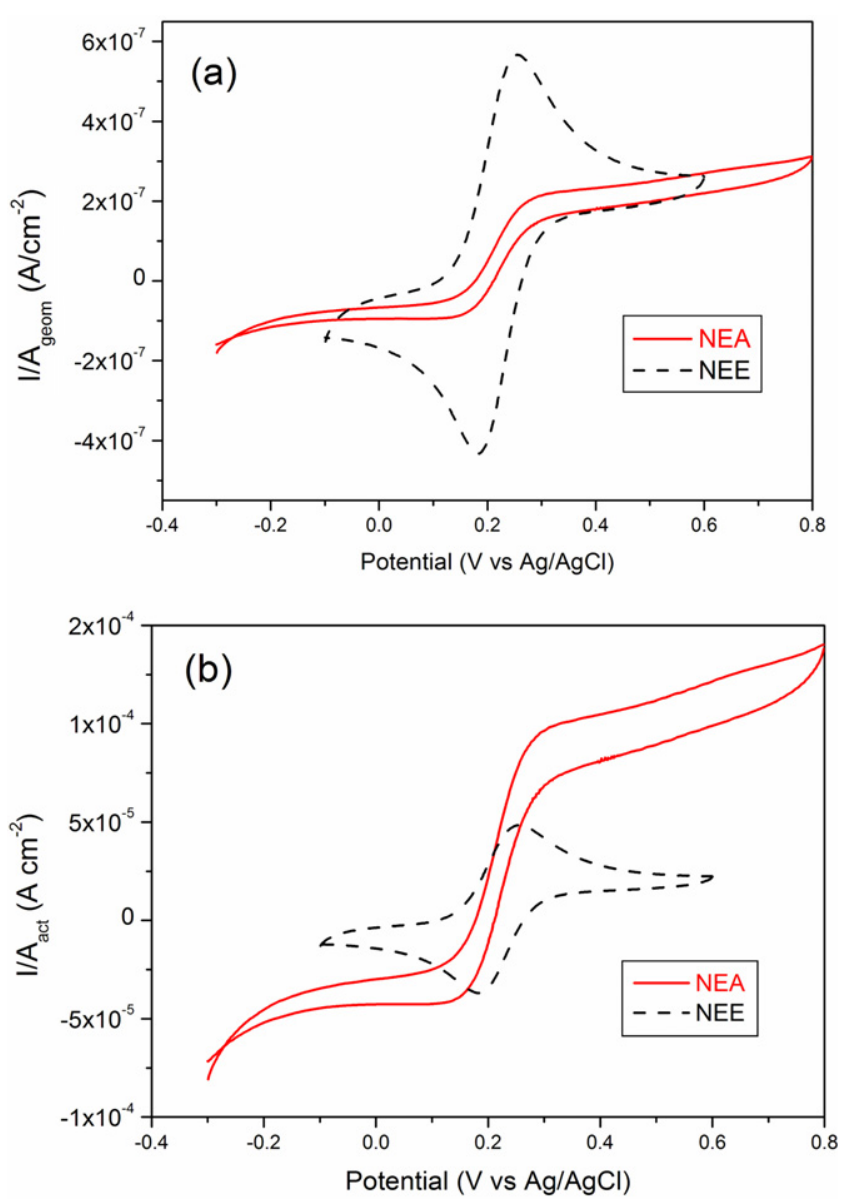

Figure 5. CVs recorded at an NEA (full line) and at an NEE (dashed line) plotted using current densities calculated with respect to the geometric area (a) and active area (b).

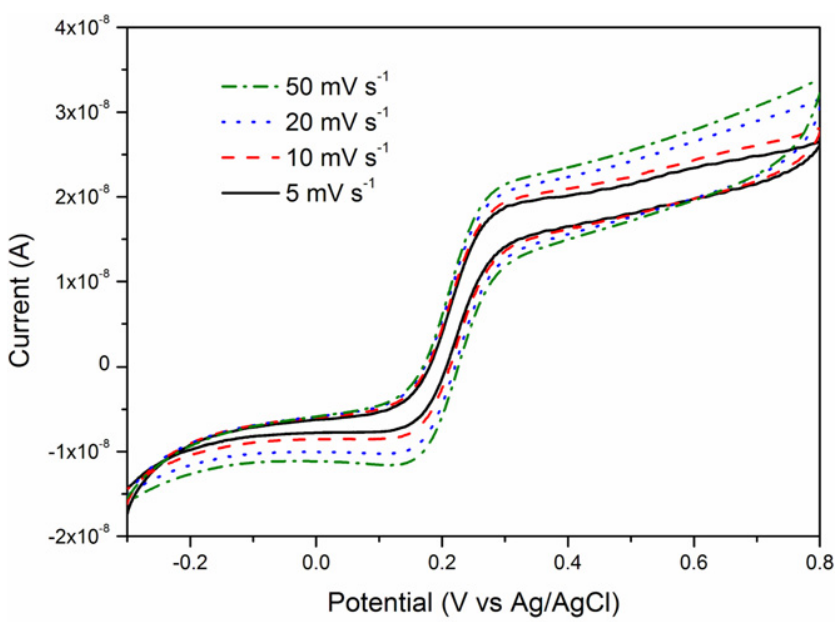

Figure 6. $\mathrm{CV}$ s recorded in $10^{-4} \mathrm{M} \mathrm{FE}$ and $0.5 \mathrm{M} \mathrm{NaNO}_{3}$. Scan rates: 5 (full line), 10 (dash line), 20 (dot line) and $50 \mathrm{mV} \mathrm{s}^{-1}$ (dash-dot line). Geometrical characteristics: as in figure 3 and table 1.

$50 \mathrm{mV} \mathrm{s}^{-1}$ reflects the radial diffusion of redox molecules from outside the pores, whereas the peak-shaped $\mathrm{CVs}$ for $v \sim 500-1000 \mathrm{mV} \mathrm{s}^{-1}$ originate from linear diffusion within the nanopores. Figure 7(b) presents the dependence of the 

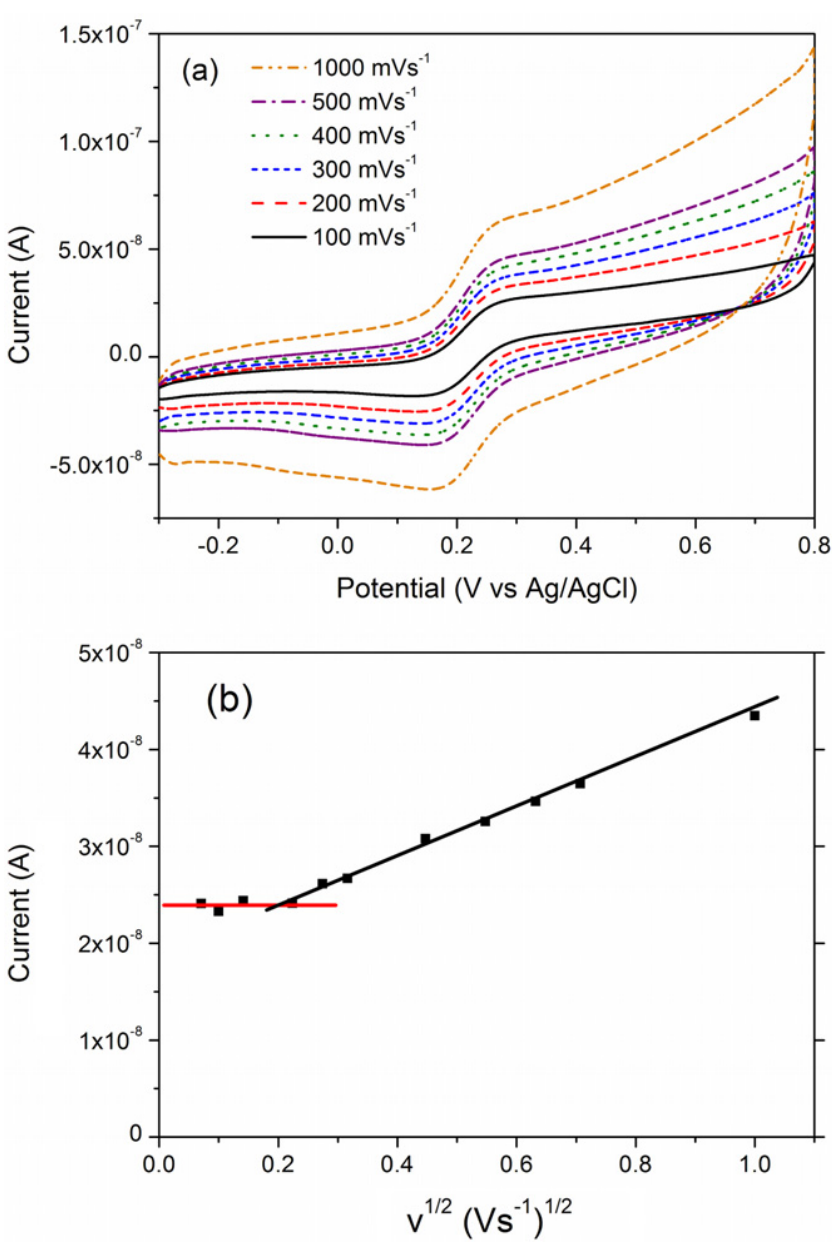

Figure 7. $\mathrm{CV}$ s recorded in $10^{-4} \mathrm{M} \mathrm{FE}$ and $0.5 \mathrm{M} \mathrm{NaNO}_{3}$. Scan rates: (a) 100, 200, 300, 400, 500 and $1000 \mathrm{mV} \mathrm{s}^{-1}$ (larger current $=$ higher scan rate). Geometrical characteristics: as in figure 3, table 1. (b) Dependence of the maximum current on the square root of the scan rate.

maximum current (i.e. the limiting current in a sigmoidal CV and the peak current in a peak-shaped $\mathrm{CV}$ ) on the square root of the scan rate. At low scan rates $\left(v \leqslant 50 \mathrm{mV} \mathrm{s}^{-1}\right)$ the current is almost constant and then it increases up to reaching a linear dependence with the square root of the scan rate at high scan rates $\left(v>200 \mathrm{mV} \mathrm{s}^{-1}\right)$. Once again, the constancy of the plateau current at low scan rates confirms, under such conditions, a pure radial diffusion behaviour. On the other hand, peak-shape and dependence of $I_{\mathrm{p}}$ on $v^{1 / 2}$ at high scan rates, agrees with linear active diffusion within the restricted volume of the recessed pores. Similar behaviour was recently observed by Ito's group, when studying the cyclic voltammetric behaviour at ensembles of recessed nanoelectrodes, prepared from track-etched polycarbonate membranes [40, 41].

The behaviour observed at our NEAs appears better defined than the one reported for PMMA-NEAs by Sandison and Cooper [12], in that, with our NEAs a well defined radial diffusion regime is achieved at scan rates lower or equal to $50 \mathrm{mV} \mathrm{s}^{-1}$ while for the NEAs in [25], mixed diffusion conditions seem to rule the voltammetric behaviour, even at scan rates as low as $10 \mathrm{mV} \mathrm{s}^{-1}$.

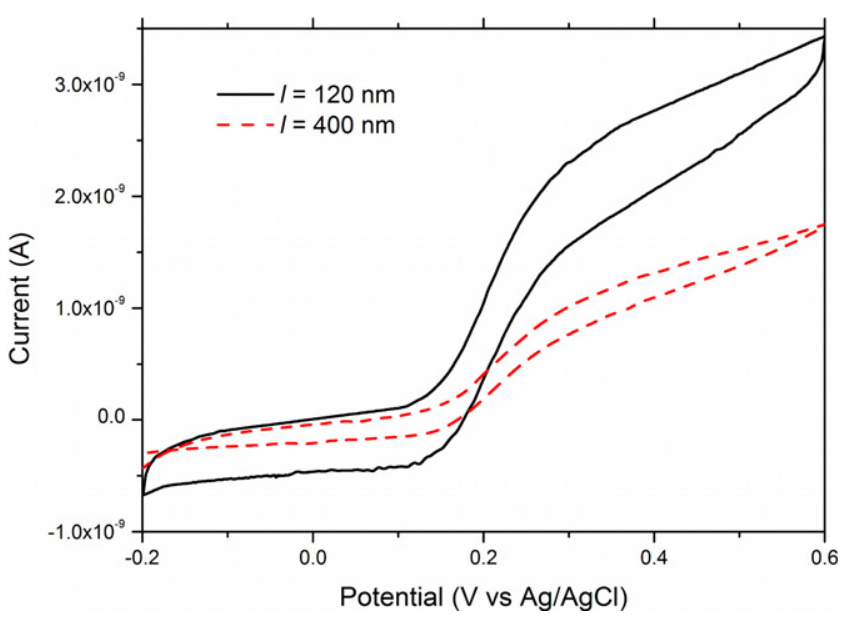

Figure 8. CVs recorded at NEAs in $10^{-4} \mathrm{M}$ FE, $0.5 \mathrm{M} \mathrm{NaNO}_{3}$, with nanoelectrode radius $r=75 \mathrm{~nm}$, recessed $l=120 \mathrm{~nm}$,

$L=l / r=1.6$ (full line) and $l=400 \mathrm{~nm}, L=l / r=5.3$ (dashed line); the distance centre-to-centre of each nanoelectrode $(d)$ is $3 \mu \mathrm{m}$ and the overall array is $300 \mu \mathrm{m} \times 300 \mu \mathrm{m}$; the scan rate is $10 \mathrm{mV} \mathrm{s}^{-1}$.

From a theoretical viewpoint, the $\mathrm{CV}$ patterns at our NEAs are in agreement with what was predicted by Guo and Lindner [21] according to which recessed NEA behaviour is determined by the values of the adimensional parameters $\delta=$ $d / r$ and $L=l / r$, where $d$ is the centre-to-centre distance between two adjacent nanoelectrodes in the array, $r$ is the nanoelectrode radius and $l$ is the recession depth. In the case of the NEA of figures 4 and $5, \delta=40$ and $L=1.3$. From the plot presented in figure 5 of [21] one can conclude that the minimal $\delta$ value to observe the pure radial regime, when $L=1.3$, is approximately $\delta=11$. This means that the $\delta$ value of our NEAs (equal to 40) is large enough to prevent any cross-talking between the nanoelectrodes, at low scan rates.

The effect of the recession on the electrochemical behaviour of the arrays was investigated by changing the recession depth by electrochemical deposition of different thicknesses of gold within the pores. The comparison of the voltammograms recorded at $10 \mathrm{mV} \mathrm{s}^{-1}$ at an NEA with nanoelectrodes of $75 \mathrm{~nm}$ and recession depths of $120 \mathrm{~nm}$ and $400 \mathrm{~nm}$, are shown in figure 8 by the full and dashed lines, respectively. In both cases the voltammograms are sigmoidally shaped. According to the model proposed by Bond et al for a single recessed microelectrode [42], the steady state limiting current at recessed electrodes (acting individually) is a function of both the disc radius, $r$, and the recession depth, $l$, and is given by

$$
i_{\text {lim }}=4 \pi n F C D r^{2} /(4 l+\pi r)
$$

where $n$ is the number of electrons exchanged, $F$ is the Faraday constant, $C$ is the analyte concentration and $D$ is the diffusion coefficient. According to equation (1), the limiting current decreases by increasing the recession depth; for the case of the NEAs of figure 8 , the theoretical ratio between the current values calculated by equation (1) is

$$
i_{(120 \mathrm{~nm})} / i_{(400 \mathrm{~nm})}=2.56 \text {. }
$$


The same ratio, calculated from experimental steady state currents in figure 8 , measured at the potential of $500 \mathrm{mV}$, is 2.30, which is in good agreement with the theoretical value. The evidence that the model developed for an individual recessed microelectrode fits well for our array of a very large number (11000) of nanoelectrodes, confirms that in our NEA each nanoelectrode behaves individually and that boundary effects as well as possible fabrication defects on individual nanoelectrodes are statistically negligible.

With respect to membrane templated NEEs, NEAs obtained by EBL show important advantages, such as exactly controlled geometry and the possibility to achieve the pure radial diffusion regime. The behaviour of PC-based NEAs was stable and reproducible over a period of several months. In particular, measurements performed with the same NEA in the same experimental conditions $\left(10^{-4} \mathrm{M}\right.$ FE in $\left.0.5 \mathrm{M} \mathrm{NaNO}_{3}\right)$ over a time span of eight months gave a maximum range of variability in steady state currents within $6 \%$.

\section{Conclusions}

Polycarbonate spin-coated on gold was shown to behave as a superb e-beam resist, with a wide exposure dose window (1000 to $10000 \mu \mathrm{C} \mathrm{cm}^{-2}$ ) at $30 \mathrm{kV}$ acceleration voltage and with a wide development temperature window (from room temperature to $60^{\circ} \mathrm{C}$ ). High resolution nanolithography of polycarbonate enabled the fabrication of ordered arrays of electrochemical nanoelectrodes of $75 \mathrm{~nm}$ radius; the recession depth of the nanoelectrodes can be controlled at will by performing an additional electroplating step. Obtained NEAs furnish well defined voltammetric signals, controlled by pure radial diffusion with no cross-talking between the electrodes; the observed electrochemical behaviour agrees with what was expected on the basis of recent theoretical models.

These characteristics, together with the good time stability and reproducibility, indicate that PC-based NEAs can be applied for the development of advanced electrochemical nanosensors, which can be prepared by exploiting the wide range of functionalization protocols available for polycarbonate.

\section{Acknowledgments}

Support by MIUR (project PRIN 2008MWHCP2) is gratefully acknowledged. We thank Dr Giulia Pecchielan for performing some preliminary experiments.

\section{References}

[1] Menon V P and Martin C R 1995 Anal. Chem. 67 1920-8

[2] Ugo P, Moretto L M and Vezzà F 2002 ChemPhysChem 3 917-25

[3] Ugo P and Moretto L M 2007 Handbook of Electrochemistry ed C Zoski (Amsterdam: Elsevier) p 678

[4] Arrigan D W M 2004 Analyst 129 1157-65

[5] Scopece P, Baker L A, Ugo P and Martin C R 2006 Nanotechnology 17 3951-6

[6] De Leo M, Kuhn A and Ugo P 2007 Electroanalysis 19 227-36
[7] Cao 1 X, Yan P S, Sun K and Kirk D W 2009 Electroanalysis 21 1183-8

[8] Jeoung E, Galow T H, Schotter J, Bal M, Ursache A, Touminen M T, Stafford C M, Russel T P and Rotello V M 2001 Langmuir 17 6396-8

[9] Chailapakul O and Crooks R M 1995 Langmuir 11 1329-40

[10] Errachid A, Mills C A, Pla-Roca M, Lopez M J, Villanueva G, Bausells J, Crespo E, Teixidor F and Samitier J 2008 Mater. Sci. Eng. C 28 777-80

[11] Lanyon Y H, De Marzi G, Watson Y E, Quinn A J, Gleeson J P, Redmond G and Arrigan D W M 2007 Anal. Chem. 79 3048-55

[12] Sandison M E and Cooper J M 2006 Lab. Chip 6 1020-5

[13] Losilla N S, Martinez J and Garcia R 2009 Nanotechnology 20475304

[14] Losilla N S, Oxtoby N S, Martinez J, Garcia F, Garcia R, Mas-Torrent M, Veciana J and Rovira C 2008 Nanotechnology 19455308

[15] Albonetti C, Martinez J, Losilla N S, Greco P, Cavallini M, Borgatti F, Montecchi M, Pasquali L, Garcia R and Biscarini F 2008 Nanotechnology 19435303

[16] Brunetti B, Ugo P, Moretto L M and Martin C R 2000 J. Electroanal. Chem. 491 166-74

[17] Hulteen J C, Menon V P and Martin C R 1996 J. Chem. Soc. Faraday Trans. 92 4029-32

[18] Ugo P, Moretto L M, De Leo M, Doherty A P, Vallese C and Pentlavalli S 2010 Electrochim. Acta 55 2865-72

[19] De Leo M, Moretto L M, Buriez O and Ugo P 2009 Electroanalysis 21 392-8

[20] Davies T J and Compton R G 2005 J. Electroanal. Chem. 585 63-82

[21] Guo J and Lindner E 2009 Anal. Chem. 81 130-8

[22] Pereira F C, Moretto L M, De Leo M, Boldrin Zanoni M V and Ugo P 2006 Anal. Chim. Acta 575 16-24

[23] Ugo P, Moretto L M, Bellomi S, Menon V P and Martin C R 1996 Anal. Chem. 68 4160-5

[24] Pozzi-Mucelli S, Zamuner M, Tormen M, Stanta G and Ugo P 2008 Biosens. Bioelectron. 22 1900-3

[25] Godino N, Borrise X, Munoz F X, del Campo F J and Compton R G 2009 J. Phys. Chem. C 113 11119-25

[26] Huang X-J, O’Mahony A M and Compton R G 2009 Small $7776-88$

[27] Lee H J, Beriet C, Ferrigno R and Girault H H 2001 J. Electroanal. Chem. 502 138-45

[28] Amatore C, Oleinik A I and Svir I 2009 Anal. Chem. 81 4397-405

[29] Ueno K, Hayashida M, Ye J-Y and Misawa H 2005 Electrochem. Commun. 7 161-5

[30] Finot E, Bourillot E, Meunier-Prest R, Lacroute Y, Legay G, Cherkaoui-Malki M, Latruffe N, Siri O, Braunstein P and Dereux A 2007 Ultramicroscopy 97 441-9

[31] Zamuner M, Pozzi-Mucelli S, Tormen M, Stanta G and Ugo P 2008 Eur. J. Nanomed. $133-6$

[32] Pecchielan G 2010 Master Thesis University Ca' Foscari of Venice, Venice (Italy)

[33] Harnett C K, Coates G W and Craig H C 2001 J. Vac. Sci. Technol. B $192842-5$

[34] Rucker V C, Havenstrite K L, Simmons B A, Sickafoose S M, Herr A E and Shediac R 2005 Langmuir 21 7621-5

[35] Souplet V, Desmet R and Melnyk O 2009 Bioconjug. Chem. 20 550-7

[36] De Leo M, Pereira F C, Moretto L M, Scopece P, Polizzi S and Ugo P 2007 Chem. Mater. 19 5955-64

[37] Apel P 2001 Radiat. Meas. 34 559-66

[38] Guillot G and Rondelez F 1981 J. Appl. Phys. 52 7155-64

[39] Krishnamoorthy K and Zoski C G 2005 Anal. Chem. 77 5068-71

[40] Ito T, Audi A A and Dible G P 2006 Anal. Chem. 78 7048-53

[41] Neluni D M, Perera T and Ito T 2010 Analyst 135 172-6

[42] Bond A M, Luscombe D, Oldham K B and Zoski C G 1988 J. Electroanal. Chem. 249 1-14 